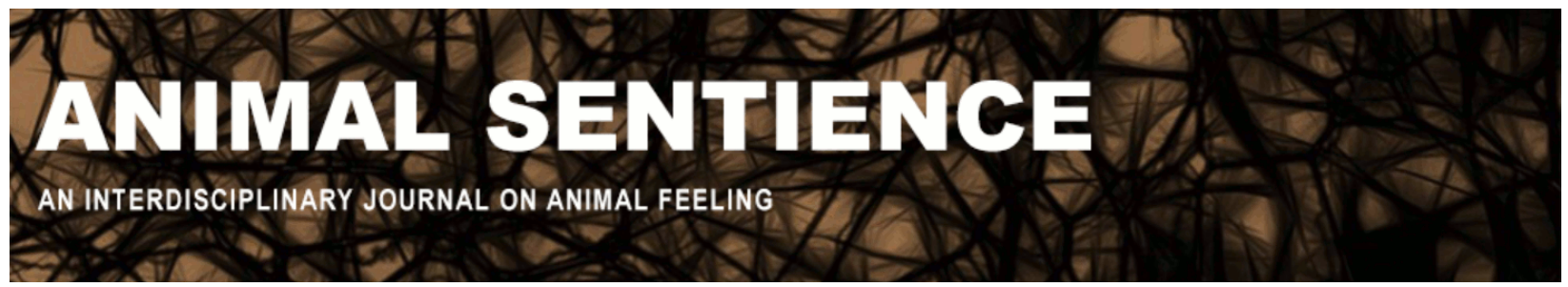

Chapman, Colin A. and Huffman, Michael A (2019) Refining thoughts about human/nonhuman differences. Animal Sentience 23(48)

DOI: $10.51291 / 2377-7478.1452$

Date of submission: 2019-05-20

Date of acceptance: 2019-05-31

(c) (†)

This article has appeared in the journal Animal

Sentience, a peer-reviewed journal on animal

cognition and feeling. It has been made open access,

free for all, by WellBeing International and deposited

in the WBI Studies Repository. For more information,

please contact

wbisr-info@wellbeingintl.org.

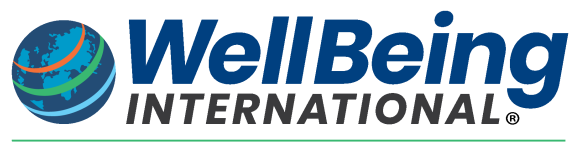

SOLUTIONS FOR PEOPLE, ANIMALS AND ENVIRONMENT 


\title{
Refining thoughts about human/nonhuman differences
}

Response to Commentary on Chapman \& Huffman on Human Difference

\begin{abstract}
Colin A. Chapman
Department of Anthropology, McGill University, Montreal, QC, Canada, Shaanxi Key Laboratory for Animal Conservation, Northwest University, Xi'an, China School of Life Sciences, University of KwaZulu-Natal, South Africa

\author{
Michael A. Huffman \\ Section of Social Systems Evolution \\ Primate Research Institute \\ Kyoto University, Japan
}

Abstract: Our commentators come from many fields and disciplines and express highly divergent views, illustrating broad interest in the question. From the breadth of comments, we have identified two recurring themes, which we focus on here. The first is a preponderance of cautionary remarks about evaluating the differences between humans and nonhuman animals. The second concerns whether considering animals as worthy of moral consideration is one of many useful tools for conservationists trying to prevent extinction, habitat destruction, and climate change.
\end{abstract}

Colin A. Chapman's research focuses on how the environment influences animal abundance and social organization. Given their plight, he has applied his research to conservation. He has conducted research in Kibale National Park in Uganda for 30 years, contributed to the park's development and protection, and has devoted great effort to promoting conservation by helping the rural communities. Website

Michael A. Huffman, a tenured faculty member at the Primate Research Institute of Kyoto University, Japan, has published on over 15 primates and other mammals in Japan, Taiwan, Sri Lanka, India, Vietnam, China, Bangladesh, Tanzania, Uganda, Guinea, South Africa, and Brazil. Website
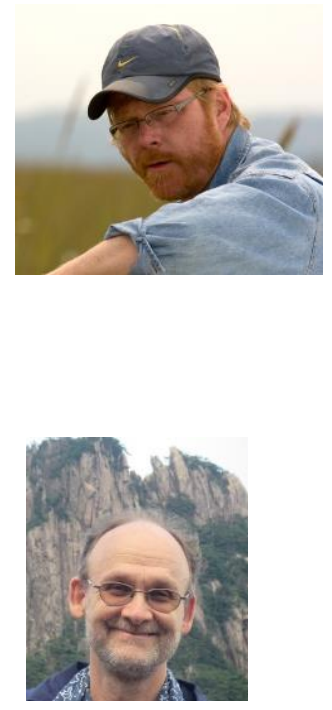

We would like to start our response by thanking all the commentators for engaging so thoughtfully with our question "are humans fundamentally different from nonhuman animals?" (Chapman \& Huffman, 2018). We hope the readers benefited as much as we did from the diversity of perspectives and disciplines represented by the responses to our target article. CAC drafted our response in Kibale National Park Uganda, where there are monkeys in the trees, grey parrots flying overhead, and elephants visiting most nights. There are also poachers hunting elephants for ivory, pangolins being taken for medicinal uses, and 
chimpanzees and elephants being maimed when a limb or trunk is caught in a snare (Figure 1). MAH has worked for years in similar situations, and both of us are actively engaged in a variety of conservation programs, such as building health clinics, conservation education, training the next generation of conservationists, and ecotourism projects. Our experience no doubt influences our perspectives and has led to our optimistic views as pointed out by Fischer.

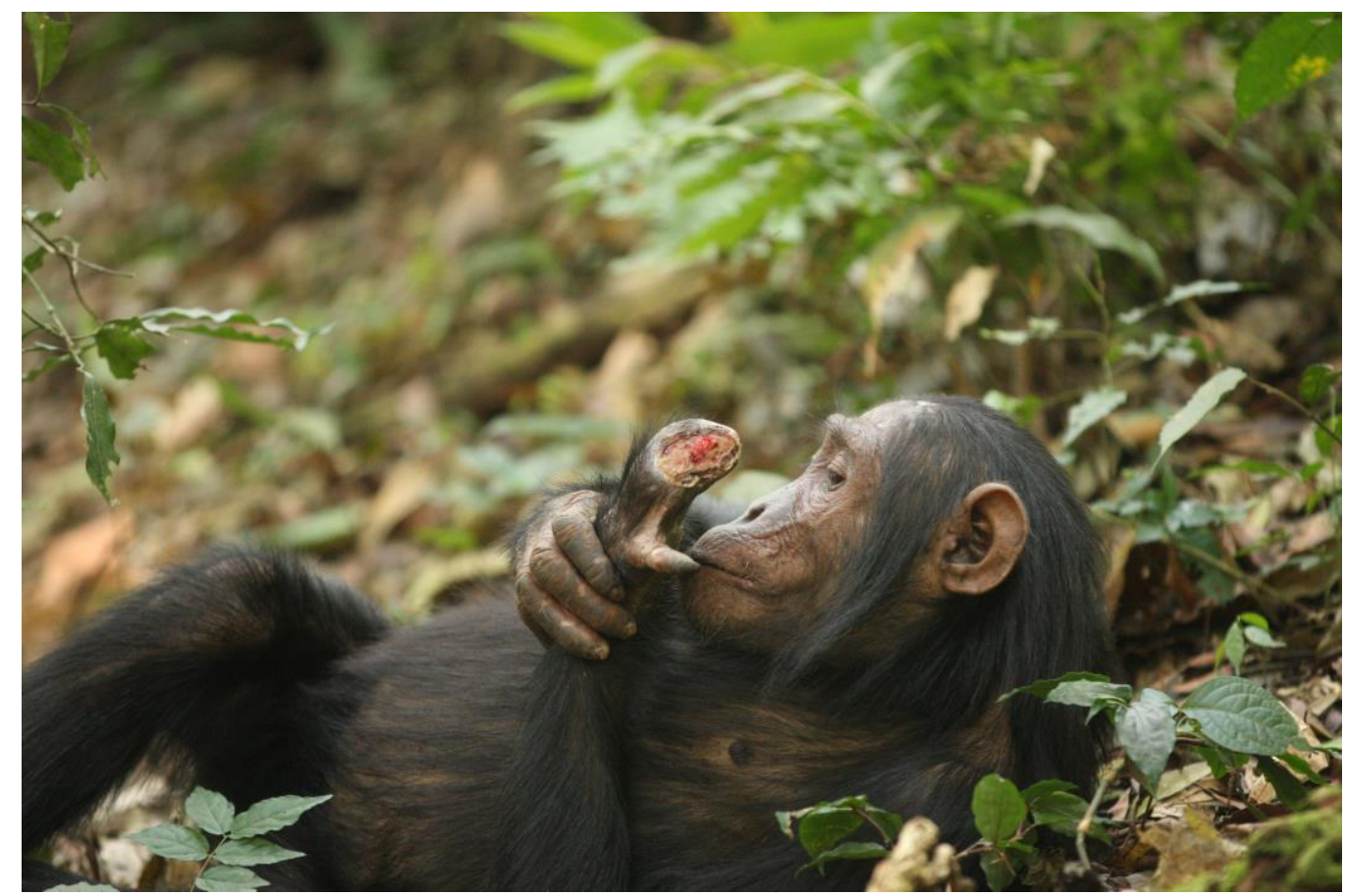

Figure 1: A chimpanzee in Kibale National Park, Uganda, who lost his fingers after stepping in a snare. The individual pulled the snare wire from its support, but the wire remained attached to the animal's wrist, causing infection and the loss of the figures. Photo by Sylvan Whitmore.

Following good quantitative principles, we initially tried to make a check sheet of the commentators who view humans as not being superior to animals, but see each species as having its own unique traits, and those commentators who view humans as unique and superior. We soon gave up on this endeavour, as there were so many divergent views and statements that it was impossible to say on what side of the debate people were on. These highly divergent views likely stem from the many different fields that commentators come from: Anthropology, Psychology, Unit of Ethics and Human-Animal Studies, Biology, Behavioural Science, Logic, Ethics, and Philosophy of Science, Computing Science, Veterinary Science, Department of International Business, Economics, and many more. Coming from this diversity of fields, it is hardly surprising there is little concordance of opinion. However, the fact that scholars from such a diversity of fields commented indicates that this is an important question of general interest (Merskin).

This diversity of fields also reveals a huge variety of perspectives, which makes providing a cogent response extremely difficult. We have thus elected to focus on two recurring themes. The first involves a number of cautionary remarks concerning how we evaluate the differences between humans and nonhuman animals. For example, BenzSchwarzburg outlined a number of studies we were unaware of and pointed out that there 
is a cognitive dissonance - meaning that humans choose to eat higher on the food chain but do not acknowledge the pain and suffering that this choice results in for the animals we are inhumanely housing and killing.

Several commentators point out the inappropriateness of defining human superiority by the traits humans view as important (Bar-Hen-Schweiger \& Henik; Monsó; Ng; Blystad; Hood \& Giddens). For example, claims for human superiority are often made based on our intellect or language (McGrew) - but is this appropriate when the animals may not need to develop these traits? Furthermore, the traits scholars are discussing are extremely hard to grasp, and as Benvenuti points out, even our own thinking and feelings can be beyond our grasp to understand (see also Kiley-Worthington). Several of the commentaries pointed out the need to consider anatomical (Criscione \& Keenan), physiological (Iotchev \& Costa), developmental (Bartsch), and evolutionary (Fawcett \& McGreevy; Hall; Ross; Wallner; Palagi) factors.

One of the most poignant cautionary remarks is aptly expressed by the title of the commentary provided by Broude - "Phooey on comparisons". The crux of her argument is that even if humans are unique or superior, it does not justify cruelty. This was pointed out by several commentators (Colombo; Shackelford; Woodruff; Vonk; Paez; Freeman; Lazarus; Edmondson; Johannsen; Ristau; Wilson). We agree, and we have engaged in activities to reduce the suffering of wild animals caused by human actions (e.g., promoting snare removal programs; Figure 1) and developing noninvasive methods of measuring the effect of human and environmentally induced sickness and stress. However, from a practical perspective, it is worth educating the general public about how remarkable animals are and how humans are not so superior and should not deny animals' moral rights. Some cultures in the tropics do not see the problem with hunting using cruel means or destroying animal habitat: "after all they are just animals". CAC was once talking to a poacher who had left a duiker (small forest ungulate) to hang at the end of a snare wire until it died after 2 days. He saw no problem with that because after all, they are just animals. On the other hand, religion sometimes protects animals as gods or deities (Nahallage \& Huffman, 2013); for these followers, even stepping on bugs is seen as a disrespectful act. For people who have not thought that animals have moral rights, it is important to point out how similar animals can be to humans. As Colombo points out, "Once we understand we know very little about other animals, we will learn to treat them with respect and humanity". For hunters and foresters to take into account the moral rights of animals, educating them about humans not being unique and superior will be an important step.

The second common theme of a number of the commentators concerned conservation. We disagree with a point raised by a number of the scholars (Hermanson; Edmondson; McGrew), and most poignantly stated by Pepperberg, that "Animal sentience is not enough to motivate conservation". Edmondson states that "... it is a matter of some regret that a campaign of education about the sentience of non-human animals may not do much to address the cruelty to which they are subject." Yet we have witnessed many instances where wild primates are viewed as similar to humans and elephants as being very intelligent. Human communities have a positive attitude to these species and their habitats, engaging in conservation action. It is our opinion that if people can relate to animals as interesting creatures, it increases the probability that conservation programs will succeed. For example, primates have repeatedly been used as flagship species (Simberloff, 1998) to change people's attitudes about forest areas and promote conservation projects that protect 
areas from deforestation or poaching (Strier, 2010; Strier et al., 2017; Cheyne, 2009; Lammertink et al., 2003; Xiang et al., 2011). The apes play a particularly important role (Williams et al., 2000). The presence of great ape research and the potential of associated ecotourism played key roles in the creation of national parks, such as Gombe and Mahale in Tanzania and Kibale, Bwindi, and Mgahinga Gorilla National Park in Uganda. Without the use of gorillas and chimpanzees as flagship species, some of these parks would not exist today. The importance of apes to local people stems at least in part from respect for the animal and their resemblance to people (Bortolamiol et al., 2018). With this respect, animals like apes and cetaceans can be used (Simberloff, 1998) to promote public interest and raise sympathy and funding for conservation.

Of course, respecting animals or viewing a species as sentient is not sufficient to ensure action on conservation; it is just one tool in a conservation biologist's tool kit. As Pepperberg points out, many people hunting bushmeat are doing so to feed their families; viewing a species as sentient is not going to stop a father from trying to feed his children. Thus, conservationists must often rely on park guards, education programs, ecotourism, and health clinics to promote positive park/people relationships. They must help the fathers develop other means (e.g., better farming practices) to obtain food for their families. A campaign to educate people about the moral rights of animals is a step in the right direction, however. Without it, other conservation actions will be much less successful. Respect for animals is a foundation of conservation globally.

Whereas adults may not always get the message, educating children through science field courses and local village awareness programs about the lives of animals in their home surroundings can make a difference (Takenoshita \& Maekawa, 2012). In high altitude subsistence-farming villages in the Himalayas of NW India, langurs cause seasonal damage to agricultural crops, and are hence strongly persecuted. In one village, before 2015, children would often throw stones at the langurs along the road, copying the behavior of their parents. A young Indian primatologist started a conservation awareness program for elementary school children and told them about the daily lives of the troop members she was studying, literally in their backyards, pointing out each individual by name. This personalized the monkeys and the children began to show interest in particular individuals, drawing pictures of the langur families instead of lone individuals. By 2017, when langurs would come to their home gardens, instead of throwing stones they would follow them and look for their favorite individuals. Simple acts like this have the potential to change local attitudes to animals $(\mathrm{H}$. Nautiyal, personal communications)

In contrast to Pepperberg, Edmondson, McGrew, and Hermanson, other commentators such as Schoof \& L'Allier, Fischer, Rollin, and Kopnina all appear, at least partially, to be of the opinion that if we stop thinking that human beings are superior to animals, we could be better positioned to address various problems like species loss, climate change, and deforestation. We agree - if great apes and forest elephants are viewed with respect and as being worthy of moral consideration, then large tracts of forest would need to be protected; this would protect biodiversity in the system and stop or reduce deforestation and the release of carbon dioxide that deforestation causes (Chapman et al., Submitted). Deforestation in the tropics releases 861,000,000 metric tons of carbon into the atmosphere a year, which represents between 8 and $15 \%$ of the total annual carbon emissions (Houghton \& Nassikas, 2018). This is six times the amount released by all of the cars and trucks on Canadian roads in a year. Treating wild animals and their habitats with respect could go a 
long way toward solving a number of the earth's most pressing environmental problems. As Schoof \& L'Allier state, emphasizing the similarities between humans and many animals can appeal to people's heads and hearts, and it is by changing people's hearts that positive action can occur. On a similar note, scientists have realized we know little about animals, and we believe that once we understand their nature and abilities better and can communicate these things to the public, we take a huge step towards learning to treat them with respect and humanity (Colombo).

\section{References}

Bar-Hen-Schweiger, M., \& Henik, A. (2019) Intelligence as mental manipulation in humans and nonhuman animals. Animal Sentience 23(31)

Bartsch, K. (2019) Developmental aspects of capacities. Animal Sentience 23(16)

Benvenuti, A. (2018) Good news: Humans are neither distinct nor superior. Animal Sentience 23(3)

Benz-Schwarzburg, J. (2018) We don't want to know what we know. Animal Sentience 23(12)

Blystad, M. H. (2018) Human-like behavior and cognition: Not a good starting point. Animal Sentience 23(11)

Bortolamiol, S., Krief, S., Chapman, C. A., Kagoro, W., Seguya, A., \& Cohen, M. (2018) Wildlife and spiritual knowledge at the edge of protected areas: Raising another voice in conservation. Ethnobiology and Conservation, 7, 1-16.

Broude, G. J. (2019) Phooey on comparisons. Animal Sentience 23(29)

Chapman, C. A., \& Huffman, M. A. (2018) Why do we want to think humans are different? Animal Sentience 23(1)

Chapman, C. A., Bicca-Marques, J. C., Dunham, A. E., Fan, P., Fashing, P. J., Gogarten, J. F., Guo, S., Huffman, M. A., Kalbitzer, U., Ma, C., Matsuda, I., Omeja, P. A., Sengupta, R., Serio-Silva, J., Yamato, T., \& Stenseth, N. C. (Submitted) Restoration provides hope for the world's primates. BioScience.

Cheyne, S. M. (2009) Challenges and opportunities of primate rehabilitation - gibbons as a case study. Endangered Species Research, 9, 159-165.

Colombo, M. (2018) How to foster respect for animals? Superiority, dissimilarity, and prejudice. Animal Sentience 23(9)

Criscione, M. J., \& Keenan, J. P. (2019) Our brains make us out to be unique in ways we are not. Animal Sentience 23(38)

Edmondson, W. H. (2018) Is superiority a necessary aspect of cruelty? Animal Sentience 23(15)

Fawcett, A., \& McGreevy, P. (2018) What sets us apart could be our salvation. Animal Sentience 23(14)

Fischer, B. (2018) Individuals in the wild. Animal Sentience 23(8)

Freeman, C. P. (2019) Taking exception to human exceptionalism. Animal Sentience 23(32)

Hall, T. F. (2018) Why humans are different. Animal Sentience 23(7)

Hermanson, S. (2019) Is human uniqueness fake news? Animal Sentience 23(39)

Hood, S. B., \& Giddens, S. (2019) Phenotypic similarity and moral consideration. Animal Sentience $23(35)$

Houghton, R. A., \& Nassikas, A. A. (2018) Negative emissions from stopping deforestation and forest degradation, globally. Global Change Biology, 24, 350-359.

Iotchev, I. B., \& Costa, K. M. (2019) Animal cognition: Quantity has a quality of its own. Animal Sentience 23(44)

Johannsen, K. (2019) Are some animals also moral agents? Animal Sentience 23(27)

Kiley-Worthington, M. (2019) Anthropomorphism is the first step. Animal Sentience 23(30)

Kopnina, H. (2019) Anthropocentrism: Practical remedies needed. Animal Sentience 23(37) 
Lammertink, M., Nijman, V., \& Setiorini, U. (2003) Population size, Red List status and conservation of the Natuna leaf monkey Presbytis natunae endemic to the island of Bunguran, Indonesia. Oryx, $37,472-479$.

Lazarus, J. (2019) Moral relevance of cognitive complexity, empathy and species differences in suffering. Animal Sentience 23(43)

McGrew, W. C. (2019) Humans have always been unique! Animal Sentience 23(28)

Merskin, D. (2019) Across the great divide. Animal Sentience 23(41)

Monsó, S. (2019) Humans are superior - by human standards. Animal Sentience 23(17)

Ng, Y-K. (2019) Human superiority is obvious but does not justify cruelty. Animal Sentience 23(36)

Paez, E. (2019) Humans may be unique and superior - and that is irrelevant. Animal Sentience 23(26)

Palagi, E. (2019) Sharing emotions builds bridges between individuals and between species. Animal Sentience 23(33)

Pepperberg, I. M. (2019) Animal sentience is not enough to motivate conservation. Animal Sentience 23(22)

Ristau, C. A. (2018) Insulting words: "They are animals!". Animal Sentience 23(10)

Rollin, B. (2018) Human superiority?. Animal Sentience 23(5)

Ross, D. (2018) Two fallacies in comparisons between humans and non-humans. Animal Sentience 23(13)

Schoof, V. A. M., \& L'Allier, S. (2019) Mobilizing heads and hearts for wildlife conservation. Animal Sentience 23(42)

Shackelford, T. K. (2018) Can they suffer? Animal Sentience 23(4)

Simberloff, D. (1998) Flagships, umbrellas, and keystones: Is single-species management passe in the landscape era? Biological Conservation, 83, 247-257.

Strier, K. B. (2010) Long-term field studies: Positive impacts and unintended consequences. American Journal of Primatology, 72, 772-778.

Strier, K. B., Possamai, C. B., Tabacow, F. P., Pissinatti, A., Lanna, A. M., de Melo, F. R., Moreira, L., Talebi, M., Breves, P., \& Mendes, S. L. (2017) Demographic monitoring of wild muriqui populations: Criteria for defining priority areas and monitoring intensity. PLoS One, 12, e0188922.

Vonk, J. (2019) Unique in degree not kindness. Animal Sentience 23(21)

Wallner, B. (2019) Of course, humans are not unique!. Animal Sentience 23(25)

Williams, P. H., Burgess, N. D., \& Rahbek, C. (2000) Flagship species, ecological complementarity and conserving the diversity of mammals and birds in sub-Saharan Africa. Animal Conservation Forum, pp. 249-260. Cambridge University Press.

Wilson, V. (2018) Using anthropocentrism to the benefit of other species. Animal Sentience 23(6)

Woodruff, M. L. (2019) Sentience is the foundation of animal rights. Animal Sentience 23(18)

Xiang, Z., Yu, Y., Yang, M., Yang, J., Niao, M., \& Li, M. (2011) Does flagship species tourism benefit conservation? A case study of the golden snub-nosed monkey in Shennongjia National Nature Reserve. Chinese Science Bulletin, 56, 2553-2558. 